\title{
Controvérsias e avanços técnicos na detecção do linfonodo sentinela
}

\author{
Carlos Alberto Buchpiguel $^{*}$
}

\begin{abstract}
A medicina nuclear tem permitido, com o uso de distintos marcadores, detectar o envolvimento tumoral de linfonodos no carcinoma mamário e outras neoplasias. Contudo, uma outra aplicação que vem se solidificando na prática clínica tem sido a detecção e localização do linfonodo sentinela. Por definição, o linfonodo sentinela é considerado a primeira estação linfonodal que drena um determinado tumor. Este conceito é bastante antigo, desde que a justificativa prática para esse conceito já era discutida por Jamieson e Dobson no início do século $X X^{(1)}$. Contudo, o termo linfonodo sentinela foi primeiramente discutido por Gould et al. em um caso de carcinoma da glândula parótida ${ }^{(2)}$. Apenas em 1977 o primeiro trabalho investigando o papel prognóstico do mapeamento linfático surgiu na literatura, na avaliação de um carcinoma de pênis. Cabanas mostrou que o prognóstico de pacientes que não apresentavam infiltração no então chamado linfonodo sentinela, no período inicial de tratamento, avaliando a sobrevida em cinco anos, foi significantemente melhor do que o de pacientes que apresentavam comprometimento tumoral desse linfonodo e de outros linfonodos ${ }^{(3)}$. Já nessa época ele concluiu que quando a biópsia do linfonodo sentinela é negativa para a presença de tumor, nenhum procedimento cirúrgico adicional é necessário. Na mesma época se observava o uso de mapeamento dos vasos linfáticos com técnica cintilográfica para identificar drenagens ambíguas em casos de melanoma e para visualizar drenagem para vasos linfáticos da cadeia mamária interna em carcinoma da mama, no sentido de orientar tratamento cirúrgico ou radioterápico ${ }^{(4)}$. Embora a maioria dos tumores sólidos seja passível de ser ressecada por cirurgia quando da apresentação inicial, o prognóstico destas neoplasias está fortemente relacionado ao estado da invasão linfo-
\end{abstract}

1. Professor Associado Livre-Docente do Departamento de Radiologia da Faculdade de Medicina da Universidade de São Paulo (FMUSP). nodal loco-regional, sendo que a sobrevida é maior e o tratamento menos agressivo quando a doença encontrase localizada e restrita ao sítio primário. Infelizmente, a recorrência de doença em um linfonodo é a primeira evidência de que a doença já se disseminou para outros locais $^{(5)}$. Portanto, considerando o corpo de evidência demonstrado por trabalhos pioneiros e por outros que se seguiram na avaliação de diferentes tipos de tumores sólidos, se discute atualmente o valor desta técnica na identificação do linfonodo sentinela e na modificação do protocolo de tratamento conforme o estadiamento da doença no carcinoma mamário.

Na prática, essa pesquisa do linfonodo sentinela pode ser feita com a injeção de um corante específico, que irá ser drenado pelos linfáticos até o gânglio sentinela, ou por injeção de compostos radioativos que irão ser mapeados em tempos determinados após a injeção com uma câmara de cintilação convencional ou ser detectados à cirurgia com sondas de deteç̧ão intra-operatória especialmente projetadas para essa finalidade.

Diferentes tipos de compostos têm sido empregados para a realização da linfocintilografia ${ }^{(6-12)}$. Como é sabido que o sistema linfático, de forma geral, drena água, solutos de baixo peso molecular, macromoléculas protéicas, fragmentos de células e células inflamatórias do espaço intersticial, com posterior deságüe no sistema vascular, é imprescindível que os agentes coloidais, normalmente empregados em medicina nuclear, preencham alguns requisitos básicos, como:

Tamanho: Sabe-se que moléculas ou partículas com diâmetro entre 2,5 e 1.000 nanômetros $(\mathrm{nm})$ podem ser drenadas de forma eficiente pelo sistema linfático.

Opsonização: É importante também que essas partículas ou substâncias radiomarcadas possuam a propriedade de serem opsonizadas por uma classe de compostos que incluem componentes de complementos como C3, C4B, C5 e algumas $\alpha$ e $\beta$ globulinas. A opsonização plasmática dessas substâncias injetadas predispõe a uma 
ativação de receptores de membrana presentes em macrófagos situados ao longo das células nos sinusóides linfonodais, promovendo, assim, o processo de fagocitose.

Carga: De preferência, os compostos empregados com essa finalidade devem ter carga negativa. Após injeção intersticial, as partículas são drenadas do espaço intersticial com velocidade inversamente proporcional ao tamanho das partículas. Isto talvez explique por que alguns autores escolhem compostos coloidais que apresentam variedade de tamanho de partículas, entre 50-200 $\mathrm{nm}$, no sentido de otimizar o processo de captação. Contudo, uma série de erros pode ocorrer na mensuração do tamanho exato da partícula, em virtude de técnicas distintas, baixa estabilidade do agente após marcação com o isótopo radioativo, incubação com o sangue, etc...

Basicamente, podem ser empregados compostos inorgânicos ou orgânicos marcados com tecnécio-99m, tendo como exemplos principais o enxofre coloidal nãofiltrado (tamanho de partículas entre 5-5.000 nm), enxofre coloidal filtrado com filtro milipore (tamanho de partículas entre 100-200 nm), trissulfito de antimônio (tamanho de partículas entre 5-15 nm), nanocolóides (tamanho de partículas entre 5-80 $\mathrm{nm}$ ), dextran (tamanho de partículas entre $2-4 \mathrm{~nm}$ ), microcolóide de albumina (tamanho de partículas entre 200-2.000 nm) e fitato (tamanho de partículas entre $10-50 \mathrm{~nm}$ ). O argumento para se quantificar de forma acurada o tamanho médio das partículas é que dimensões maiores que $1.000 \mathrm{~nm}$ fazem com que a drenagem seja muito lenta, ocorrendo graus de retenção das partículas prolongados no sítio de injeção. Partículas muito pequenas poderiam escapar das estações linfonodais de primeira ordem e se concentrar em gânglios de segunda, terceira e quarta ordens ${ }^{(13)}$. Porém, ainda não se sabe adequadamente se isto pode ser considerado um aspecto negativo ou positivo, pois se acredita que um maior número de linfonodos visualizados diminuiria a taxa de resultados falso-negativos.

Uma série de fatores técnicos pode interferir com os resultados obtidos na localização do linfonodo sentinela. O primeiro fator a ser considerado é o local onde o composto coloidal marcado será injetado. Alguns autores defendem a injeção ou administração intratumoral. Contudo, esse tipo de injeção deve ser reservado para estudos localizatórios de lesões mamárias ocultas ou nãopalpáveis. Uma das razões por que se tenta evitar esse tipo de técnica quando o objetivo é apenas visualizar o linfonodo sentinela, é que muitas vezes não se identifica drenagem linfática em virtude da pressão intersticial intratumoral elevada, impedindo a visualização em tempo hábil do linfonodo sentinela. Aqueles que criticam a injeção intratumoral advogam os seguintes motivos: a) lesões tumorais apresentam modificação da estrutura tecidual de drenagem linfática, fazendo com que ocorra falhas de drenagem ou mesmo drenagem anômala; $b$ ) grandes volumes de composto radioativo podem alterar o padrão fisiológico de drenagem e fazer com que gânglios não sentinelas sejam identificados.

A injeção peritumoral permite visualizar o linfonodo sentinela de uma forma mais rápida do que a técnica de injeção intratumoral, sendo empregados, assim, menores volumes e doses de radioisótopos. Um aspecto mais comumente observado com as técnicas de injeção profunda é que se visualiza mais freqüentemente drenagem para a cadeia mamária interna. Alazraki et al. relataram que a visualização de gânglios da cadeia mamária interna pode ser conseguida com técnica de injeção intratumoral em até $30 \%$ dos $\operatorname{casos}^{(9)}$. Embora não se saiba, até o presente momento, o real impacto prognóstico da identificação de linfonodos sentinelas na cadeia mamária interna em pacientes com estádio I, certamente essa característica da técnica pode ser considerada uma vantagem em comparação com a técnica de injeção subdérmica ou intradérmica, ou mesmo periareolar.

A técnica de injeção subdérmica ou intradérmica apresenta vantagens quanto à facilidade de injeção, menor custo (não necessidade de mamografia com estereotaxia ou ultra-sonografia para administração do radiofármaco) e maior rapidez na identificação do linfonodo sentinela. Com essa técnica pode-se visualizar o linfonodo sentinela em cerca de 30-45 minutos após a injeção do radioindicador, em contraste com técnicas de injeção peritumoral, nas quais se obtêm tempos de espera de até oito horas para a visualização de drenagem linfática. A única inconveniência da técnica é que ela não permite visualizar a cadeia mamária interna. Outra vantagem que poderia ser mencionada com o uso de colóides filtrados é que com essa técnica necessita-se de volume e dose significativamente menores dos que os empregados com as técnicas de injeção profunda.

Como a técnica de injeção subdérmica ou intradérmica necessita a presença de lesão palpável, com o objetivo de orientar o quadrante da mama para se administrar o radiofármaco, pacientes com lesões mamárias ocultas, ou que já foram manipuladas localmente por mamotomia, ou mesmo pacientes já submetidos à cirurgia com indefinição do tamanho da lesão, podem se beneficiar de uma técnica de administração intradérmica que independe da localização do tumor. Como todo o processo de drenagem da mama invariavelmente passa pelo território areolar para depois drenar para a cadeia axilar, a administração superficial neste território, teoricamente, poderia substituir a drenagem intradérmica orien- 
tada pela palpação ${ }^{(14)}$. Embora as evidências na literatura sejam limitadas ainda, um trabalho recente avaliando 117 mulheres com mamas já manipuladas demonstrou que a técnica de injeção periareolar é tão sensível quanto a técnica de injeção intradérmica, e capaz de predizer o status axilar com alta acurácia ${ }^{(15)}$. Porém, é importante lembrar que com essa técnica não é possível a visualização de drenagem para a cadeia mamária interna, tampouco se pode empregar o método para a localização de lesões mamárias ocultas, quando a mama ainda não foi manipulada.

No entanto, embora a taxa de visualização do linfonodo sentinela seja bastante adequada com as técnicas disponíveis atualmente, alguns aspectos controversos ainda persistem. A simples identificação do linfonodo não necessariamente fornece garantias que se trata do verdadeiro linfonodo sentinela, nem garante que não existam outros sentinelas. A única forma de afirmar que essa técnica certamente traz benefícios prognósticos, ou melhor, não implica risco prognóstico para o paciente, é definir o grau de sobrevida, isenta de complicações ou recidivas, após vários anos de seguimento clínico. Outro aspecto, não menos importante, é que freqüentemente se visualiza mais do que um linfonodo sentinela, e isto pode fazer com que o patologista tenha que executar uma análise mais detalhada, com múltiplos cortes, de cada um dos linfonodos, diminuindo a acurácia da análise no período intra-operatório. Porém, a técnica de injeção periareolar tem-se mostrado a mais prática, mais rápida e provavelmente sem perda de eficácia na identificação do linfonodo sentinela, quando não se está considerando a drenagem para cadeia mamária interna.

\section{REFERÊNCIAS}

1. Jamieson JK, Dobson JF. Lectures on the lymphatic system of the stomach. Lancet 1907;i:1061-6.
2. Gould EA, Winship T, Philbin PH, Kerr HH. Observations on a "sentinel node" in cancer of the parotid. Cancer 1960;13:77-8.

3. Cabanas RM. An approach for the treatment of penile carcinoma. Cancer 1977;39:456-66.

4. Ege GN. Internal mammary lymphoscintigraphy in breast carcinoma: a study of 1072 patients. Int J Radiat Oncol Biol Phys 1977;2:755-61.

5. Carr I. Lymphatic metastasis. Cancer Metastasis Rev 1983;2:30717.

6. Cox CE. Clinical relevance of serial sectioning of sentinel nodes and the detection of micrometastatic nodal disease in breast cancer. Ann Surg Oncol 1998;5:297-8.

7. Keshtgar MRS, Ell PJ. Sentinel lymph node detection and imaging. Eur J Nucl Med 1999;26:57-67.

8. Morton DL, Chan AD. The concept of sentinel node localization: how it started. Semin Nucl Med 2000;30:4-10.

9. Alazraki NP, Styblo T, Grant SF, Cohen C, Larsen T, Aarsvold JN. Sentinel node staging of early breast cancer using lymphoscintigraphy and the intraoperative gama-detecting probe. Semin Nucl Med 2000;30:56-64.

10. Alex JC, Krag DN. Gamma-probe guided localization of lymph nodes. Surg Oncol 1993;2:137-43.

11. Paganelli G, DeCicco C, Cremonesi M, et al. Optimized sentinel node scintigraphy in breast cancer. Q J Nucl Med 1998;42:4953.

12. Roumen RM, Geuskens LM, Valkenburg JG. In search of the true sentinel node by different injection techniques in breast cancer patients. Eur J Surg Oncol 1999;25:347-51.

13. Birdwell RL, Smith KL, Betts BJ, Ikeda DM, Strauss HW, Jeffrey SS. Breast cancer: variables affecting sentinel lymph node visualization at preoperative lymphoscintigraphy. Radiology 2001; 220:47-53.

14. Borgstein PJ, Meijer S, Pijpers RJ, van Diest PJ. Functional lymphatic anatomy for sentinel node biopsy in breast cancer: echoes from the past and the periareolar blue method. Ann Surg 2000;232:81-9.

15. Maza S, Thomas A, Winzer KJ, et al. Subareolar injection of technetium-99m nanocolloid yields reliable data on the axillary lymph node tumour status in breast cancer patients with previous manipulations on the primary tumour: a prospective study of 117 patients. Eur J Nucl Med Mol Imaging 2004;31: $671-5$. 